\title{
A Comparative Clinical Study of Mandibular Incisor Decrowding Using Different Pre-Adjusted Edgewise Brackets with Different Interbracket Span
}

Abhimanyu Rohmetra1, Niharika Gupta², Sakshi Mahajan³, Saksham Narainia4, Ishita Gupta ${ }^{5 *}$

${ }^{1}$ Consultant Orthodontist, Department of Orthodontics and Dentofacial Orthopaedics, Jammu, J\&K, India. 2PG Student, Department of Oral and Maxillofacial Surgery, J.N. Kapoor DAV(C) Dental College,

Yamunanagar, Haryana, India.

3Practising Dental Surgeon, Jammu, J\&K, India.

${ }^{4} P G$ Student, Department of Conservative Dentistry and Endodontics, M.R. Ambedkar Dental College and Hospital, Bangalore, Karnataka, India.

5Intern, Institute of Dental Sciences, Sehora, Jammu, J\&K, India.

Research article

Address for Correspondence Author

Dr. Ishita Gupta, Intern, Institute of Dental Sciences, Sehora, Jammu, J\&K, India.

E-mail: orthodontistjammu@gmail.com

Crossref doi: https://doi.org/10.36437/ijdrd.2020.2.2.P

\section{ABSTRACT}

Introduction: Aim of the present was to determine and compare the efficiency of different pre-adjusted edgewise brackets with different Inter-bracket span in mandibular incisor decrowding and to determine and compare the amount of incisor proclination during decrowding if any.

Material and Method: 20 patients were selected and divided into two groups, group I with Double width brackets (3M Unitek Gemini Series) 0.018" slot with Roth prescription and group II with Mini Uni-Twin Bracket. (3M Unitek) 0.018" slot with Roth prescription. Pretreatment records were taken included lateral cephalogram, study models, and photographs. Little's irregularity index was calculated for both groups also IMPA was calculated for both at regular intervals and finally compared with post-treatment records.

Result: Little' irregularity index in group II was having a slightly higher ratio. Both Group I and Group II cases demonstrated an increase in the proclination of the lower anterior during decrowding.

Conclusion: The Mini Uni Twin brackets were found to align the lower anterior faster. Mini Uni Twin brackets are comparatively efficient in the lower anterior decrowding.

Keywords: Decrowding, Mandibular, Incisor, Interbracket Span.

\section{Introduction}

The importance of aligning has received a great deal of attention from the orthodontist. Newer wires and innovations in the bracket systems have simplified and reduced the time span of the aligning stage. ${ }^{1}$ Angle mentioned the importance of a wide Interbracket distance to decrease the wire's stiffness. Essentially, wire stiffness depends upon at least three factors and the first one is the material itself, the second one includes the cross-section of the wire, and lastly the length of wire between brackets; the Interbracket Span. ${ }^{2}$ Though the 
new wires certainly represent a step forward, they are only a partial step towards total efficiency. The basic change needs to be more in the appliance than in the wires. Minimum attention along with the chairside, minimum discomfort to the patient, more rapid a better-controlled alignment was observed with Mini Uni-twin brackets. $^{3}$ The current study was undertaken to determine and compare the efficiency of different pre-adjusted edgewise brackets with different Inter-bracket span in mandibular incisor decrowding and to determine and compare the amount of incisor proclination during decrowding if any. ${ }^{4}$ Table 1 discusses the advantages and disadvantages of single-width brackets and double-width bracket.

\begin{tabular}{|c|c|c|}
\hline $\begin{array}{l}\text { Type of } \\
\text { Brackets }\end{array}$ & Advantages & Disadvantages \\
\hline $\begin{array}{l}\text { Single width } \\
\text { bracket }^{5}\end{array}$ & $\begin{array}{l}\text { - Increased interbracket distance - } \\
\text { aligning and leveling forces within the } \\
\text { physiologic limits. } \\
\text { Bracket placement on smaller and } \\
\text { crowded teeth more convenient. } \\
\text { - Difficulty to get full bracket engagement } \\
\text { is considerable reduced. } \\
\text { - Size of the first rectangular wire- not } \\
\text { necessarily the smallest wire light } \\
\text { torquing forces-reduced root } \\
\text { resorption }\end{array}$ & $\begin{array}{l}\text { - Inadequate tipping and rotational } \\
\text { control } \\
\text { - The presence of wings made } \\
\text { bonding difficult } \\
\text { - Reduced torqueing efficiency } \\
\text { - Friction between the bracket slot } \\
\text { and the arch wire increased - } \\
\text { contact angle } \\
\text { - Debonding forces strained the } \\
\text { enamel wall above the acceptable } \\
\text { limits }\end{array}$ \\
\hline $\begin{array}{l}\text { Double width } \\
\text { bracket }^{6}\end{array}$ & $\begin{array}{ll}\text { - } & \text { Control of root position } \\
\text { - } & \text { Rotational and tipping control } \\
\text { - } & \text { Torquing efficiency }\end{array}$ & $\begin{array}{l}\text { - Bracket placement and full } \\
\text { bracket engagement in crowded } \\
\text { lower anterior was less } \\
\text { convenient } \\
\text { - Greater friction }\end{array}$ \\
\hline
\end{tabular}

Table 1: The Advantages and Disadvantages of Single Width Brackets and Double Width Bracket.

\section{Material and Method}

\section{Criteria for patient selection:}

- Number: 20 patients, 10 from each group.

- Malocclusion: Class I / Class II

- Age: $14-20$ years.

- Lower incisor discrepancy: 4 - 9mm according to Little's Irregularity score.

- Favorable inclination of the canine

- Absence of any oral habit

- Good oral hygiene

- Without any malformation in the anterior teeth

- Patients that had their bands and / or attachments broken were not included the study. The selected samples were grouped as follows. (TABLE: 2) 


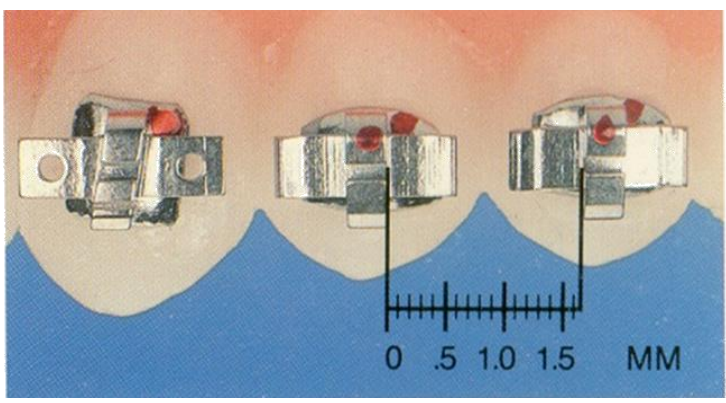

Figure 1: The Single Width Bracket

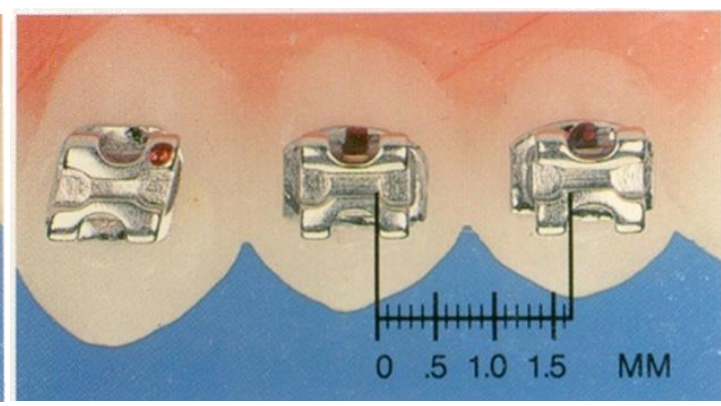

Figure 2: The Mini Uni Twin Bracket

\section{Group I (Figure1)}

Double width brackets (3M Unitek Gemini

Series) 0.018 " slot with Roth prescription

$2.4 \mathrm{~mm}$ ( Actual width of the bracket)
Group II (Figure2)

Mini Uni-Twin Bracket. (3M Unitek) 0.018" slot with Roth prescription

$2.5 \mathrm{~mm}$ (Precision part was $1 \mathrm{~mm}$ )

\section{Clinical Procedure}

Table: 2 Grouping of Selected Samples

The clinical procedure started with the taking of pretreatment records of the selected patients who fulfil our inclusion criteria, here study models, lateral cephalogram, and intra-oral photographs of the patients were taken. After taking all the pretreatment records conventional bonding procedures were undertaken, followed by placing Laceback using $0.009^{\prime \prime}$ SS wire. Heat-activated $0.016^{\prime \prime}$ NiTi $\left(37^{\circ}\right)$, Ortho form III. (3M Unitek).6 Once the wire was ligated the participants of the study were asked to visit for a follow-up visit every 14 days and were advised to consult the concerned doctor immediately if there were any loose brackets or bands.

Next step was an evaluation of the study cast, in this Little's Irregularity Score was first measured. A Digital Vernier Caliper measuring to $0.02 \mathrm{~mm}$ was used for this purpose. This method involved measuring the linear displacement of the anatomic contact point as distinguished from the clinical contact point. A perfectly aligned arch from the mesial aspect of the left canine to the mesial aspect of the right canine theoretically would have had a score of 0 , and a score higher than this would indicate the greatest displacement and more crowding. 7 The measurements were obtained directly from the mandibular cast rather than intra-orally since proper positioning of the caliper was essential for consistent accuracy. The mandibular cast was viewed from above sighting down on to the edge of the anterior teeth (Fig 3). The caliper was held parallel to the occlusal plane while the beaks were lined up with contact points to be measured. The mesiodistal spacing was disregarded, provided the teeth in question was in proper arch form; if spacing, as well as displacement or rotations, was noted only the labiolingual displacement from the proper arch form was recorded. The patients were recalled every 14 days and impressions were made for study casts evaluation as per the Little's irregularity index and were tabulated, till the Little's irregularity score was "0" indicating a well-aligned arch.

After evaluating the study cast, Evaluation of the Incisor proclination during decrowding was taken up. The pre-treatment and post-treatment lateral cephalograms were traced in the usual manner for the incisor mandibular plane angle (IMPA) (Fig4). The difference between the pre-treatment and post-treatment lateral cephalogram was calculated for the change in the axial inclination of the lower incisor during decrowding. Fisher's Exact test was applied to compare a proportion of cases decrowded at different intervals between Group I and Group II. 


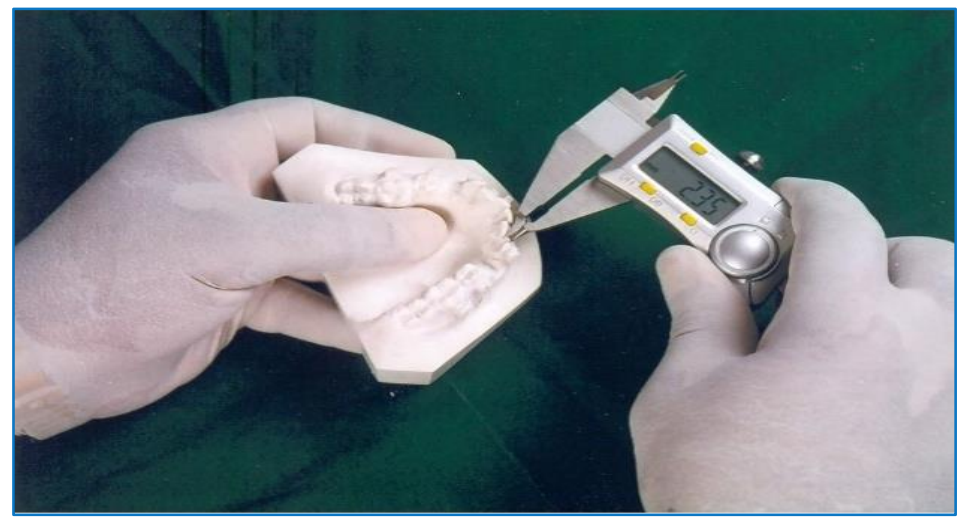

Figure 3: The Mandibular Cast was Viewed from Above Sighting Down on to the Edge of the Anterior Teeth.

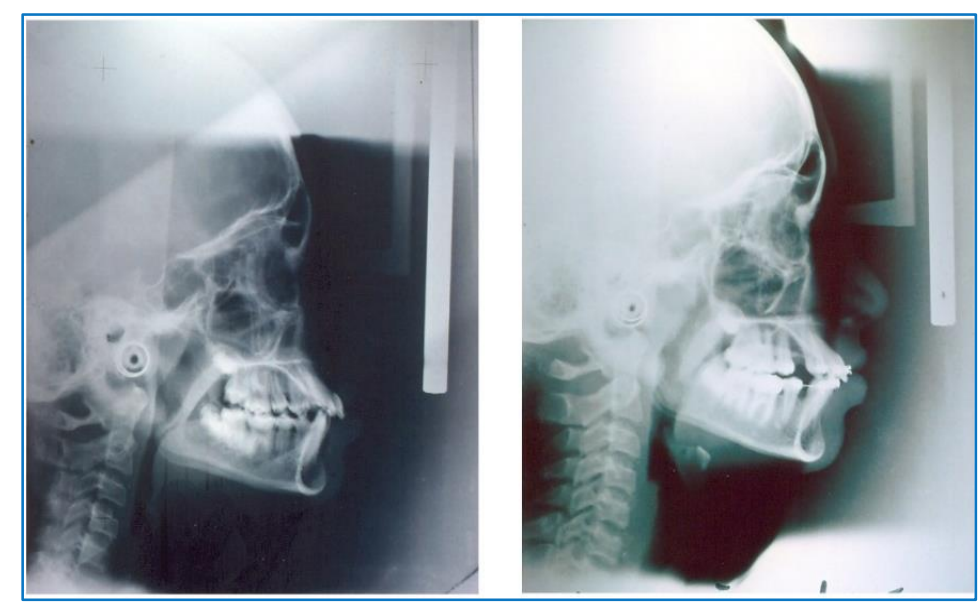

Pre-treatment Post-treatment

Figure4A: Group I Gemini Series Bracket

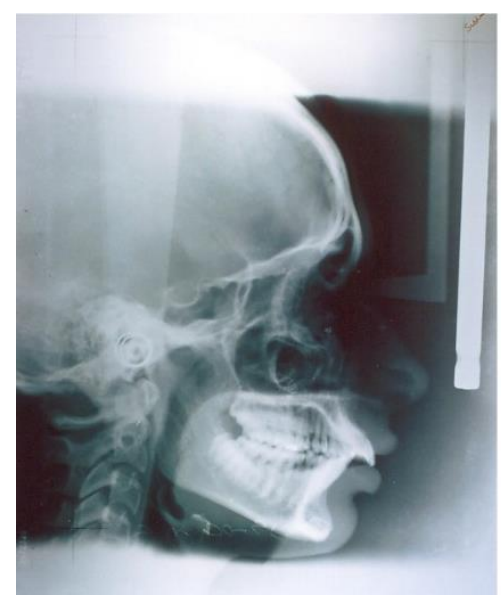

Pre-treatment

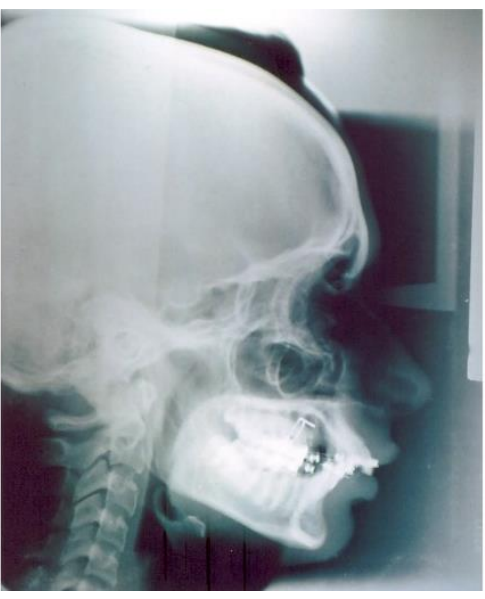

Post-treatment

Figure 4B: Group II Mini Uni Twin Bracket 


\section{Results}

The mean age of the patient for Group I was $17.1 \pm 2.6$ years and for Group II was $16.7 \pm 2.0$ years hence there was no significant difference in the mean ages between Group I and Group II ( $\mathrm{P}=0.70)$. Similarly the proportion of the male patients in both groups was similar ( $\mathrm{P}=0.58$ ). Little's Irregularity Score for a group I was $6.55 \pm 0.91 \mathrm{~mm}$ Mean \pm S.D. and for a group, II was $6.55 \pm 1.02 \mathrm{~mm}$ Mean \pm S.D.so the p-value came out to 1.00 (Table 3). Fisher's Exact test was applied to compare the proportion of cases decrowded at different intervals between Group I and Group II (Table 4) Amount of de crowding between two groups were also compared (Table 5). From Day 1 to Day 14 for a group, I Mean \pm S.D was $0.68 \pm 0.09 \mathrm{~mm}$ while for group II Mean \pm S.D was reported to be $0.94 \pm 0.15 \mathrm{~mm}$. From Day 14-Day $28 \mathrm{Mean} \pm$ S.D for a group I $(2.02 \pm 0.15 \mathrm{~mm})$ and Mean \pm S.D for group II $(2.37 \pm 0.26 \mathrm{~mm})$. From Day 28-Day $42(4.85 \pm 0.34 \mathrm{~mm})$ and Mean \pm S.D for group II $(4.85 \pm 0.34 \mathrm{~mm})$ From Day 42-Day 56 for a group I Mean \pm S.D was $6.11 \pm 0.44 \mathrm{~mm}$ while for group II Mean \pm S.D was reported to be $6.38 \pm 0.75 \mathrm{~mm}$. From Day 56-Day 70 Mean \pm S.D for a group I $(6.55 \pm 0.91 \mathrm{~mm})$ and Mean \pm S.D for group II $(6.55 \pm 1.02 \mathrm{~mm})$ While Evaluating the Incisor Mandibular Plane Angle (IMPA)The Pearson's Chi-square Test was applied and Pretreatment and post-treatment decrowding IMPA was compared. IMPA for pre-treatment for a group I (Mean \pm S.D, $94.3^{\circ} \pm 2.1^{\circ}$ ) and for group II (Mean \pm S.D, $94.0^{\circ} \pm$ $2.0^{\circ}$ ). For post-treatment for a group I (Mean \pm S.D, $95.1^{\circ} \pm 2.0^{\circ}$ ) and for group II (Mean \pm S.D, $95.8^{\circ} \pm 1.9^{\circ}$ ). The change between pre and post IMPA for a group I (Mean \pm S.D, $0.8^{\circ} \pm 0.6^{\circ}$ ) and for group II (Mean \pm S.D, $1.8^{\circ} \pm$ $0.9^{\circ}$ ) (Table 6)

\begin{tabular}{|l|l|l|l|}
\hline \multirow{2}{*}{ Variable } & Group I & Group II & \multirow{2}{*}{ P-value * } \\
\cline { 2 - 3 } & Mean \pm S.D. & Mean \pm S.D. & \\
\hline Little's Irregularity score. & $6.55 \pm 0.91 \mathrm{~mm}$ & $6.55 \pm 1.02 \mathrm{~mm}$ & 1 \\
\hline
\end{tabular}

Table: 3 Comparison of Mean Ratio of Little's Irregularity Score.

\begin{tabular}{|l|l|l|l|l|l|l|}
\hline \multirow{2}{*}{ Intervals } & \multirow{2}{*}{ Decrowding } & \multicolumn{2}{|l|}{ Group I } & \multicolumn{2}{l|}{ Group II } & \multirow{2}{*}{ P-value* } \\
\cline { 3 - 6 } & & No & $\%$ & No & $\%$ & \\
\hline \multirow{2}{*}{$1^{\text {st }}$ Day } & Yes & 0 & $0 \%$ & 0 & $0 \%$ & \multirow{2}{*}{1.00} \\
\cline { 2 - 7 } & NO & 10 & $100 \%$ & 10 & $100 \%$ & \\
\hline \multirow{2}{*}{$14^{\text {th }}$ Day } & YES & 0 & $0 \%$ & 0 & $0 \%$ & \multirow{2}{*}{1.00} \\
\cline { 2 - 7 } & NO & 10 & $100 \%$ & 10 & $100 \%$ & \\
\hline $28^{\text {th }}$ Day & YES & 0 & $0 \%$ & 0 & $0 \%$ & \multirow{2}{*}{1.00} \\
\cline { 2 - 6 } & NO & 10 & $100 \%$ & 10 & $100 \%$ & \\
\hline
\end{tabular}

12 International Journal of Drug Research and Dental Science 


\begin{tabular}{|l|l|l|l|l|l|l|}
\hline \multirow{2}{*}{$42^{\text {nd }}$ Day } & YES & 0 & $0 \%$ & 0 & $0 \%$ & \multirow{2}{*}{1.00} \\
\cline { 2 - 6 } & NO & 10 & $100 \%$ & 10 & $100 \%$ & \\
\hline \multirow{2}{*}{$56^{\text {th }}$ Day } & YES & 1 & $10 \%$ & 3 & $30 \%$ & \multirow{2}{*}{0.65} \\
\cline { 2 - 6 } & NO & 9 & $90 \%$ & 7 & $70 \%$ & \\
\hline \multirow{2}{*}{$70^{\text {th }}$ Day } & YES & 5 & $50 \%$ & 10 & $100 \%$ & \multirow{2}{*}{0.03} \\
\cline { 2 - 6 } & NO & 5 & $50 \%$ & 0 & $0 \%$ & \\
\hline
\end{tabular}

Table: 4 Comparison of Proportion of Cases Decrowded at Different Intervals Between Group I and Group II.

\begin{tabular}{|l|l|l|l|}
\hline \multirow{2}{*}{ Variable } & Group I & Group II & \multirow{2}{*}{ P-value * } \\
\cline { 2 - 3 } & Mean \pm S.D. & Mean \pm S.D. & \\
\hline Day 1-Day 14 & $0.68 \pm 0.09 \mathrm{~mm}$ & $0.94 \pm 0.15 \mathrm{~mm}$ & $<0.0001$ \\
\hline Day 14-Day28 & $2.02 \pm 0.15 \mathrm{~mm}$ & $2.37 \pm 0.26 \mathrm{~mm}$ & 0.002 \\
\hline Day 28-Day42 & $4.85 \pm 0.34 \mathrm{~mm}$ & $5.38 \pm 030 \mathrm{~mm}$ & 0.005 \\
\hline Day 42-Day 56 & $6.11 \pm 0.44 \mathrm{~mm}$ & $6.38 \pm 0.75 \mathrm{~mm}$ & 0.35 \\
\hline Day 56-Day 70 & $6.55 \pm 0.91 \mathrm{~mm}$ & $6.55 \pm 1.02 \mathrm{~mm}$ & 1.00 \\
\hline
\end{tabular}

Table: 5 Comparison of Amount of Decrowding at Different Intervals Between Group I and Group II.

\begin{tabular}{|l|l|l|l|}
\hline \multirow{2}{*}{ Variable } & Group I & Group II & \multirow{2}{*}{ P-value* } \\
\cline { 2 - 3 } & Mean \pm S.D & Mean \pm S.D & \\
\hline IMPA- Pre & $94.3^{\circ} \pm 2.1^{\circ}$ & $94.0^{\circ} \pm 2.0^{\circ}$ & 0.75 \\
\hline IMPA- Post & $95.1^{\circ} \pm 2.0^{\circ}$ & $95.8^{\circ} \pm 1.9^{\circ}$ & 0.44 \\
\hline IMPA- Change & $0.8^{\circ} \pm 0.6^{\circ}$ & $1.8^{\circ} \pm 0.9^{\circ}$ & 0.01 \\
\hline
\end{tabular}

Table: 6 Comparison of Pretreatment and Post Decrowding IMPA 


\section{Discussion}

Little (1975) developed an index for assessing the degree of crowding in the mandibular arch.7 This method involved measuring the linear displacement of the anatomic contact point as distinguished from the clinical contact point. Single brackets increase interbracket distance about $50 \%$ and reduce wire stiffness (roughly the difference in stiffness between stainless steel and nickel-titanium). ${ }^{8}$ All the calculated values were recalculated 3 times and a mean was taken out to avoid any measurement errors. It was clear from table 3 that the Little' irregularity index in group II was having a slightly higher ratio.

The number of cases decrowded on the 70th day of the study was statistically significant in favor of Group II. This was most probably because of the increased interbracket span and was in correlation to Schudy and Schudy. ${ }^{9}$

Hocevar ${ }^{10}$ stated that alignment of crowded incisor whether accomplished by looped or plain arch wire, had a reciprocal action between the canines and incisors, tipping the former distally and the latter anteriorly, thus having the same effect as the anchor bends on the incisor. Both Group I and Group II cases demonstrated an increase in the proclination of the lower anterior during decrowding.

\section{Conclusion}

The Mini Uni Twin brackets were found to align the lower anteriors faster - statistically significant. The amount of decrowding occurring was faster at various intervals in cases with the Mini Uni Twin brackets- a statistically significant at interval 1, 2, 3 and 4. Cases with Mini Uni twin brackets had statistically significant amount of proclination of the lower anteriors $\left(0.8^{\circ} \pm 0.3^{\circ}\right)$ after decrowding - clinical significance could be questionable (lesser than $1^{\circ}$ )

Mini Uni Twin brackets are comparatively efficient in the lower anterior decrowding but further comparative clinical studies need to be performed, with an increase in the sample size and also the number of parameters to prove its total clinical efficiency. ${ }^{11}$ Since we will never find a completely ideal appliance we must rely on the one that has the maximum advantages and the one that is the best accord with the biologic requirements.

\section{References}

1. Creekmore TD, Comment reference in intrabracket space and intrabracket distance article AJODO 1990 97(4):33.

2. Creekmore TD, The importance of interbracket width in orthodontic tooth movement JCO 1976 37:530-34.

3. Tweed C.H, The Frankfurt mandibular plane angle in orthodontic diagnosis, classification, treatment planning and prognosis AJ0 1946 32(4):175-230.

4. Irvine R, Power S, McDonald F, The effectiveness of lace back ligatures: a randomized controlled clinical trial J Orthod 2004 31(4):303-11.

5. Tidy: Frictional forces in fixed appliances AJODO 1989 96(3):249-54.

6. Kusy R, Dilley G, Elastic property ratios of a triple stranded stainless steel arch wire American Journal of Orthodontics and Oral Surgery 1984 86(3):177-88.

7. Little R.M, The irregularity index: a quantitative score mandibular anterior alignment American Journal of Orthodontics and Oral Surgery 1975 68(5):554-63.

8. Schudy G, Bracket design and wire flexibility JCO 1990 45:106-14.

9. Schudy G, Schudy F.: Intrabracket space and interbracket distance: critical factors in clinical orthodontics AJODO 1989 96(4):281-94. 
10. Hocevar R, Orthodontic force systems: technical refinements for increased efficiency American Journal of Orthodontics and Oral Surgery 1982 81(1):1-11.

11. Gupta N, Rohmetra A, Ishita. Patient Preference and Compliance between Hawley Retainers and Vacuum-Formed Retainers following Orthodontic Treatment. J Adv Med Dent Scie Res 2020; 8(5):119-129.

How to cite this Article: Abhimanyu Rohmetra1, Niharika Gupta2, Sakshi Mahajan3, Saksham Narainia4, Ishita Gupta5*: A Comparative Clinical Study of Mandibular Incisor Decrowding Using Different Pre-Adjusted Edgewise Brackets with Different Interbracket Span

Int. J. Drug Res. Dental Sci., 2020; 2(2):8-15.

Crossref doi: $h$ ttps://doi.org/10.36437/ijdrd.2020.2.2.P

Source of Support: Nil, Conflict of Interest: None declared.

Received: 20-2-2020 Revised: 15-3-2020 Accepted: 19-4-2020 